Acta Orientalia Academiae Scientiarum Hung. Volume 54 (2-3), 339-360 (2001)

\title{
LE PHENOMENE DE METAGRAMMATISME \\ DANS LE MONDE MUSULMAN : APPROCHE D’UNE ETUDE COMPARATIVE
}

\author{
XAVIER LUFFIN* \\ (Bruxelles)
}

\begin{abstract}
Certaines minorités religieuses partagent avec la société au sein de laquelle elles vivent des traits culturels marquants : habitudes vestimentaires, coutumes, tradition orale et surtout langue. Dans le monde musulman, et en particulier dans la sphère culturelle turque, certaines de ces minorités - les Karamanlıs, les Urums, les Krimchaks, les Arméno-kipchaks... - se sont distinguées de la culture environnante d'une manière particulière : l'utilisation, pour noter la langue qu'ils partagent avec ladite culture, d'un autre alphabet. Celui-ci est emprunté à la « culture de référence », c'est-à-dire la communauté avec laquelle ils partagent la même religion. Cette nouvelle graphie a souvent donné lieu à une riche littérature. L'adoption de cette graphie semble essentiellement traduire un désir d'affirmer leur différence confessionnelle, même si d'autres pistes peuvent être mises en évidences.

Mots clés : métagrammatisme, alphabet, religion, culture de référence, culture dominante, monde turc, monde arabe, minorités.
\end{abstract}

\section{Introduction : le métagrammatisme comme phénomène général}

Avant d'aborder cette recherche, il convient de se mettre d'accord sur le terme « métagrammatisme », néologisme dont nous donnerons la définition suivante : «adoption d'un alphabet allogène par les locuteurs d'une langue déjà pourvue d'un alphabet communément accepté ».

Les changements d'alphabet apparaissent à toutes les époques et dans diverses aires culturelles. Prenons deux exemples extrêmes au niveau géographique et temporel : d'une part, citons ces quelques tablettes d'argile contenant des textes en néoassyrien notés à l'aide de l'alphabet grec, qui furent retrouvés en Iraq et que les philologues baptisèrent graeco-babyloniaca (Geller 1983 ; Maul 1991).

D'autre part, mentionnons le cas des langues dites «adjami»-terme d'origine arabe ('ajami) qui doit être compris ici dans son sens de « étranger, allogène »-

${ }^{*}$ Xavier Luffin c/o Kana, Avenue Brugmann, 294, 1180 Bruxelles Belgique, ou Université Libre de Bruxelles, 1180 Bruxelles Belgique, ILVP - CP 110, Avenue F. Roosevelt, 50 - 1050 B, e-mail : xluffin@nirvanet.net 
c'est-à-dire des langues africaines notées à l'aide de caractères arabes, qui seront dès le $19^{\text {ème }}$ siècle notées en caractères latins. En Afrique de l'Ouest, c'est le cas du peul, du wolof (qu'on appelle d'ailleurs « wolofal » lorsqu'il est transcrit en lettres arabes) et du haoussa, et en Afrique de l'Est du kiswahili, du somali et même du malgache (Ricard 1995, p. 28 ; Malherbe 1995, p. 99), pour ne citer que les langues principales. Le cas des langues adjami mériterait une étude à lui seul, tant par son étendue géographique que par les phénomènes historiques auxquels il est lié, en l'occurrence l'évangélisation et la colonisation du continent africain.

Relevons enfin le cas inverse sur le continent où les Cape Malays d'Afrique du Sud, descendants d'esclaves musulmans apportés d'Asie par les autorités coloniales anglaises, rédigent des textes en afrikaans à l'aide de l'alphabet arabe (Kähler 1976)!

\section{Le métagrammatisme dans le monde musulman}

Nous nous limiterons toutefois ici à l'étude du métagrammatisme au sein des minorités religieuses du monde musulman, car il fallait bien se donner des limites cohérentes au niveau de la zone culturelle et temporelle à étudier. Or, la fréquence du phénomène est particulièrement remarquable dans le monde musulman, en particulier d'ailleurs dans l'Empire ottoman.

Nous aurons fréquemment recours aux expressions culture de référence et culture dominante, avec les acceptions particulières suivantes : la culture dominante est celle dans laquelle vit une minorité, généralement sous son autorité. La culture de référence est celle à laquelle cette minorité s'identifie au moins sur le plan religieux.

\section{a. Le métagrammatisme dans le monde turc}

Notons d'emblée que déjà à l'époque pré-islamique plusieurs écritures différentes furent appliquées au turc, phénomène qui trouve peu de comparaisons dans les autres domaines linguistiques, surtout si l'on prend en considération la courte durée de cette séquence temporelle, qui ne couvre en fait que quelques siècles.

Les premiers textes en langue turque connus actuellement, les stèles de l'Orhon (Mongolie) remontent au plus tôt au $8^{\text {ème }}$ siècle après J.-C. Or l'écriture utilisée dérive de l'alphabet vieux-sogdien, lui-même inspiré de l'araméen.

Les Uygurs utilisaient aussi un alphabet dérivé de l'araméen par l'intermédiaire du sogdien (Bombaci 1969, p. 33). Quelques textes rédigés en turc aux alentours du $10^{\mathrm{e} m e}$ siècle nous révèlent l'emploi de quelques autres alphabets, en l'occurrence le sogdien, le syriaque estranghelo, l'alphabet manichéen ou encore le tokharien, inspiré du brahmi indien (Samoilovitch 1934, p. 959 ; Bombaci 1969, p. 33).

Ibn Nadīm, auteur arabe du $10^{\text {ème }}$ siècle, avance dans son ouvrage intitulé Fihrist que les Bulgares, peuple turc originaire d'Asie centrale, utilisaient l'écriture manichéenne et même chinoise pour leurs documents officiels. Mais aucun texte ori- 
ginal qui permettrait de confirmer cette assertion ne nous est parvenu (Hrbek 1960, p. 1347).

Le plus ancien texte turc rédigé en caractères arabes est le dictionnaire turcarabe d'Al Kashgārī, rédigé à Baghdād vers 1040. Mais ce n'est qu'au $13^{\text {ème }}$ siècle qu'apparaissent de manière plus courante des documents turcs transcrits en alphabet arabe. Ce choix fut sans nul doute motivé par des raisons religieuses, évidentes et somme toute logiques. Il sera aussi celui des autorités ottomanes dès le $14^{\text {ème }}$ siècle et perdurera jusqu'aux premières années de la République turque, lorsque Mustafa Kemal fixera en 1928 l'adoption de l'alphabet latin (Kramers 1934, p. 967).

\section{Les métagrammatismes dans la sphère culturelle turque}

Parallèlement à l'utilisation de l'alphabet officiel - en fait l'alphabet arabe additionné de quelques caractères particuliers - quelques minorités vivant dans l'Empire ottoman se servaient d'autres écritures déjà existantes, qui les rattachaient ainsi soit à leur culture originelle, soit à celle de leurs coreligionnaires.

Ainsi, les deux principales communautés chrétiennes de l'Empire ottoman, en l'occurrence les Grecs et les Arméniens, utilisèrent souvent leurs propres alphabets pour écrire le turc en Anatolie mais aussi en Crimée et dans le Caucase (Blau 1874, p. 577 ; Türkmen 1983, p. 173). Ce fut également le cas des Juifs tatarophones de Crimée (Rosenthal non daté, pp. 574-575) et des Géorgiens du Caucase et d'Azerbaycan (Samoilovitch 1934, p. 962 ; Türkmen 1983, p. 173).

\section{Les Grecs : Karamanlis et Urums}

Les contacts entre cultures grecque et turque remontent à l'arrivée des premiers Turcs en Anatolie au $11^{\text {ème }}$ siècle. Les Turcs créèrent de petites principautés sur des territoires arrachés à l'autorité byzantine, mais la langue grecque y resta d'usage bien longtemps.

On a ainsi conservé quelques ghazāls en langue grecque transcrits en caractères arabes, dont les auteurs ne sont autres que Mawlāna Jalāl ad-dīn Rūmī et son fils Sultān Walad, célèbres poètes mystiques qui fuirent l'Iran au $13^{\text {ème }}$ siècle devant l'avancée des Mongols, et qui vinrent s'installer en Anatolie. Il semble clair que les deux poètes, qui rédigeaient leurs œuvres en arabe et en persan, ont voulu s'adresser ici au public anatolien, ayant à cet effet recours à leur langue. Le grec qu'ils utilisaient est d'ailleurs le démotique, et non la langue littéraire (Burguière - Mantran 1952, pp. $63 \mathrm{sq})$.

Mais c'est surtout au sein de l'Empire Ottoman que la culture grecque tint une place particulière. En effet, lorsque les Turcs conquirent Constantinople en 1453, ils permirent à sa population chrétienne de rester dans la capitale. Au siècle suivant, plus du tiers des habitants de la capitale était encore de confession grecque orthodoxe, proportion qui restera stable jusqu'à l'aube de la Première guerre mondiale, puisqu'en 1914 près de $40 \%$ des Stambouliotes étaient des non-musulmans (Coubage Fargues 1997, pp. 205 sq). Mais le nouveau pouvoir alla plus loin et décida aussi de 
laisser aux représentants de différentes communautés religieuses de l'Empire - du moins celles qui entrent dans la catégorie des Gens du Livre - leur prérogatives sur le plan spirituel et aussi le moyen de régler leurs affaires internes selon leurs propres lois. Dans le cas de l'Eglise orthodoxe grecque, dès 1454 le Sultan Mehmet II, le conquérant de Constantinople, confirme les droits et les privilèges du Patriarche Ghennadios, en y ajoutant la juridiction civile sur les Chrétiens de l'Empire.

Dès le $16^{\text {ème }}$ siècle, l'administration ottomane commence à désigner les communautés religieuses non-musulmanes sous le terme de millet, structure à l'intérieur de laquelle chaque communauté peut régler ses affaires internes sans intervention des autorités ottomanes. Mais la première mention du millet orthodoxe grec en tant qu'entité propre, le millet-i Rum ou Rum milleti, ne remonte qu'au milieu du $18^{\text {ème }}$ siècle (Ursinus 1993, pp. 62 sq).

A côté de ces Grecs, qui continuèrent à pratiquer leur foi orthodoxe et aussi leur langue d'origine, on rencontre quelques communautés originales, dont la plus intéressante est sans doute celle des Karamanlıs.

Le terme «Karamanlı» désignait sous l'Empire ottoman une communauté de Chrétiens de rite grec orthodoxe turcophones. Ils tiraient leur nom de leur région d'origine, Karaman, aujourd'hui la province de Konya, bien qu'on les retrouvât ailleurs en Anatolie, comme à Akşehir, Nevşehir, Burdur, Isparta, Ereğli, Içel, Ürgüp, Göreme et Ermenek (Eckmann 1991, p. 20), à Antalya, Izmir et dans la région du Pont, notamment Trabzon et bien sûr à Istanbul.

Qu'est-ce qui les distinguait alors de leurs coreligionnaires pour mériter une dénomination particulière? Leur langue et surtout leur manière d'écrire celle-ci. Les Grecs, en tant que sujets de l'Empire ottoman, connaissaient très souvent le turc, et cela encore plus à Istanbul et en Anatolie, par la force des choses. Mais les Karamanlis eux, parlaient souvent exclusivement le turc, surtout en Anatolie. Leur particularisme ne s'arrête pas là : ils transcrivaient leur langue... en caractères grecs. Hormis ce trait particulier, les Karamanlıs présentaient d'autres caractéristiques qui les éloignaient de leurs frères de religion et les rapprochaient de leurs voisins Turcs musulmans : coutumes vestimentaires, habitudes de la vie quotidienne et surtout références culturelles communes dès qu'on sort du domaine de la religion.

En effet, si la littérature karamanlı est à l'origine exclusivement religieuse (du $15^{\text {ème }}$ siècle au début du siècle passé), seuls des ouvrages de cette nature seront rédigés. Ce n'est que dans la première moitié du $19^{\text {ème }}$ siècle qu'apparaissent des livres à caractère profane : grammaires de la langue turque, manuels de géographie... (Salaville 1958, p. IX). Quelques décennies plus tard seront publiés des livres destinés aux loisirs, comme des épopées, des romans, des recueils de poésie... Malgré cette évolution, les ouvrages religieux constituent $51 \%$ des ouvrages d'avant 1900 répertoriés (Balta 1987, p. XX).

Mais l'élément intéressant qui ressort de l'analyse des livres profanes et religieux n'est pas tant leur proportion que le caractère culturel lié à l'un et à l'autre. En effet la littérature religieuse est exclusivement chrétienne et essentiellement grecque, comme on pouvait s'y attendre, alors que les ouvrages profanes sont la plupart du temps inspirés de la culture turque. 
Ce clivage sera constant et il persistera jusqu'au début de ce siècle, même si chacun des deux domaines est altéré à partir du $19^{\text {ème }}$ siècle - l'un dans sa grécité à cause du prosélytisme des protestants - qui imprimèrent de nombreux ouvrages en karamanlı en vue de convertir de nouvelles ouailles en Anatolie - et l'autre à cause des traductions de romans occidentaux.

En 1851 parait le premier journal karamanl1, prélude à une presse assez florissante, tandis que le karamanlı est aussi utilisé dans la correspondance et l'épigraphie - surtout religieuse. Enfin, les textes karamanlı présentent un intérêt linguistique particulier, car la langue utilisée est le turc anatolien populaire - très proche du turc contemporain - contrairement aux textes en turc ottoman de la même époque, saturé de termes et de tournures arabo-persans. ${ }^{1}$

Hormis les Karamanlıs, il nous faut mentionner une autre minorité similaire particulièrement intéressante. Dès le $17^{\text {ème }}$ siècle, une communauté grecque relativement importante - les Urums - est attestée dans la ville de Mariupol et ses environs, en Crimée, alors que la communauté culturelle dominante y est alors constituée par les Tatars.

Les Urums - très probablement une déformation du terme arabo-turc Rüm qui désigne les Chrétiens et plus particulièrement les Grecs - sont des Chrétiens de rite orthodoxe, mais ils sont tatarophones. Il semble que certains de ces Urums, répartis dans une quinzaine de villages aux alentours de Mariupol, parlaient encore un dialecte grec au $19^{\text {ème }}$ siècle. On les appelait les Tats, tandis que ceux qui ne parlaient que le tatar se nommaient les Bazarians (Blau 1874, p. 577).

Selon le révérend $\mathrm{R}$. Pinkerton, un missionnaire anglican qui visita la région au début du siècle passé, les Urums étaient au nombre de 53000 dans le district de Mariupol, dont 30000 âmes résidant dans la ville elle-même. ${ }^{2}$

Mais les Urums ne parlaient pas seulement le tatar, ils l'écrivaient aussi, en caractères... grecs. On a par exemple retrouvé à Odessa une traduction en «grécotatar» des Fables d'Esope, publiée à Mariupol en 1779 (Blau 1874, p. 589). Les Urums se sont-ils inspirés des Karamanlıs d'Anatolie? En tout cas, les missionnaires protestants qui circulèrent en Crimée au $19^{\text {ème }}$ siècle attestent de la présence dans la péninsule de nombreux ouvrages rédigés en karamanlı (Clogg 1968, p. 59).

\section{Les Arméniens : de l'arméno-turc aux Arméno-Klpçak(s)}

La communauté arménienne, dans ses rapports avec le monde turc, offre de nombreux points communs avec la communauté grecque : les Arméniens sont dans leur majorité de confession chrétienne - constituant une église autocéphale. Ils entretenaient des rapports avec le monde byzantin avant l'arrivée des Turcs, qu'ils connurent d'ailleurs à la même époque que les Grecs et dans des circonstances similaires. Ils furent eux aussi organisés en millet au sein de l'Empire ottoman, tandis que leurs activités commerciales et leur répartition dans les villes d'Anatolie, loin de leur foyer d'origine, constitue un autre point commun avec les Grecs.

\footnotetext{
${ }^{1}$ Pour une description plus détaillée de la culture karamanl1, voir Luffin (1998, pp. 5-99).
}

${ }^{2}$ Cité dans Clogg (1968, p. 59). 
A côté de la grande majorité des Arméniens qui, comme les Grecs, surent conserver l'usage de leur langue, il faut signaler qu'une partie non négligeable d'entre eux étaient devenus exclusivement turcophones. Ils utilisaient toutefois eux aussi les caractères arméniens pour écrire le turc, ce qui donna lieu à une très riche littérature (Berberian 1963, pp. 810 sq).

Parallèlement, les Arméniens installés dans 1'Azerbaycan voisin écrivaient de la même manière la langue vernaculaire locale, proche du turc anatolien (Dimitriev 1934, pp. 50 sq).

Mais, comme dans le chef des Karamanlıs, cette acculturation par rapport à la culture dominante ne se limitait pas au métagrammatisme. Ainsi, dès le $18^{\mathrm{eme}}$ siècle les Ashugs, équivalant aux Aş1ks turcs, chantent les exploits légendaires de grands héros anatoliens : Aslı et Kerem, Köroğlu et Aşık Garip. Ce mouvement de culture populaire prit tant d'importance qu'aux $17^{\text {ème }}$ et $18^{\text {ème }}$ siècles trois écoles d'Ashugs se créèrent en Anatolie, mais aussi en Géorgie et en Perse (Berberian 1963, p. 810).

D'autres genres littéraires, parfois plus élaborés, virent également le jour dans la culture arméno-turque : le meddah, sorte de pièce de théâtre, les recueils poétiques de nağme, comme celui que nous a laissé Elyas Musekyan, poète et marchand de la première moitié du $18^{\text {ème }}$ siècle (Türkmen 1977, pp. 278 sq; Türkmen 1983, pp. 173 sq). On a également retrouvé, dans une langue beaucoup plus élaborée, des manzum methiye en arméno-turc, louanges rédigées par des notables arméniens en l'honneur de leur Sultan, notamment Mahmut II qui régna de 1809 à 1839 (Pamukiyan 1991, p. 1053).

Dès le $18^{\text {ème }}$ siècle apparaissent également des ouvrages de médecine, de sciences naturelles, ainsi que des traductions d'auteurs étrangers comme Voltaire, Chateaubriand ou Young. Quant à la littérature religieuse, la Bible et certains ouvrages canoniques furent publiés en arméno-turc par les Mékhitaristes et les missionnaires protestants.

$\mathrm{Au}$ siècle suivant, une importante presse arméno-turque va se développer. On dénombre pas moins de quarante-cinq journaux différents édités à Istanbul entre 1855 et 1936 (Berberian 1963, p. 816).

Toutefois, l'acculturation des Arméno-Turcs se distingue de celle des Karamanlis par un point important : leur conscience de constituer une culture à part entière se manifeste plus souvent que chez leurs homologues grecs. En effet, alors que chez ces derniers la culture profane est profondément turque, les Ashugs firent quelquefois de Köroğlu un héros chrétien, de même qu'ils chantaient aussi les exploits de Cello, un bandit de grands chemins arménien qui sévissait dans la région de Kayseri (Dumézil 1938, p. 72, note 1 ; Berberian 1963, p. 812).

Une autre communauté arménienne subit une acculturation similaire dans la sphère culturelle turque : les Arméno-Kıpçaks. Il s'agit d'Arméniens parlant non pas le turc anatolien mais le kıpçak - proche du dialecte des Urums, des Krimchaks et des Karaïtes, dont nous parlerons plus loin - qui vivaient dans un premier temps en Crimée et en Ukraine, puis en Moldavie et en Pologne (Dachkévytch 1982, p. 394 ; Dachkévytch 1968, p. 329). 
En fait, la présence des Arméniens en Crimée et en Ukraine est attestée depuis le $11^{\text {ème }}$ siècle, suite aux invasions des Selcuks en Arménie. L'arrivée des Tatars au $13^{\text {ème }}$ siècle donnera lieu à une seconde vague d'émigration vers cette région, si bien que la Crimée était parfois appelée au siècle suivant Armenia Magna ou encore Armenia Maritima (Spüler 1986, p. 139b).

La turcisation de ces colonies arméniennes de la côte septentrionale de la Mer Noire s'amorça probablement dès l'arrivée des Kıpçaks, c'est-à-dire au $11^{\text {ème }}$ siècle.

Mais ce n'est qu'au $15^{\text {ème }}$ siècle que ces Arméniens deviennent réellement turcophones, tandis que les premiers cas de métagrammatisme apparaissent au siècle suivant (Dachkévytch 1982, p. 357).

A la même époque, on retrouve ces Arméniens kıpçakophones en Pologne et en Moldavie. On dénombre alors environ soixante-dix «colonies» arméniennes en Moldavie, en Ukraine et en Crimée, dont les plus importantes se situent à Lvov et à Kamenetz Podolsk (Dachkévytch 1982, pp. 82 et 362).

Dès la moitié du $17^{\text {ème }}$ siècle, ces établissements périclitent suite aux persécutions religieuses menées par les catholiques polonais désormais devenus maîtres de la région, à l'occupation turque de la Podolie dès 1670 et l'effondrement de l'économie régionale. Les Arméniens émigrent alors vers d'autres contrées ou s'assimilent à la population locale, processus qui sera achevé au $19^{\text {ème }}$ siècle (Dachkévytch 1982, pp. 330 et 366 ).

Sur le plan culturel, leur assimilation rappelle celle des Karamanlis et surtout des Urums. En effet, hormis l'éternel métagrammatisme - qui porte sur des textes exclusivement religieux, mais aussi administratifs et juridiques - ils présentent d'autres signes d'acculturation : ils portent par exemple des anthroponymes turcs au $14^{\text {ème }}$ et $15^{\text {ème }}$ siècles, puis ukrainiens et polonais. A la fin du $17^{\text {eme }}$ siècle, ces mêmes Arméno-kıpçaks laissent des documents en polonais transcrit en caractères arméniens (Dachkévytch 1982, pp. 398 sq).

Mais le brassage de population qui s'opérait à l'intérieur de l'Empire ottoman entraîna encore d'autres métagrammatismes. Ainsi, certains Arméniens qui vivaient en Anatolie orientale entourés de Kurdes étaient assez logiquement kurdophones - il en existe d'ailleurs encore actuellement, même s'ils émigrent massivement vers l'Europe occidentale. Au siècle passé, plusieurs éditions de la Bible furent imprimées à leur intention - car ils étaient restés fidèles à l'église arménienne - en langue kurde transcrite au moyen de l'alphabet arménien (Akbaş 1992, notes 162 et 270).

Dans le Caucase, il arrivait en outre que certaines stèles funéraires arméniennes soient gravées en arménien transcrit en caractères latins, voire même géorgiens (Berberian 1963, pp. 816).

\section{Les Juifs dans le monde turc : le cas des Krimchaks et des Caraïtes}

La communauté juive, présente dans les frontières de l'Empire ottoman, ne semble pas avoir utilisé l'alphabet hébreu pour transcrire la langue turque. Par contre, les Juifs de Crimée l'appliquèrent au tatar, langue turque parlée dans la région depuis l'arrivée des Kipçaks au $11^{\text {ème }}$ siècle. En effet, les Krimchaks - communauté juive 
rabbinique installée en Crimée et dont l'ethnonyme dérive d'ailleurs du nom de la péninsule - étaient tatarophones et transcrivaient leur langue en caractères hébreux (Dachkévytch 1982, p. 394).

Peut-être originaires d'Istanbul, ville qu'ils auraient quittée au $14^{\text {ème }}$ siècle, ils s'installèrent principalement à Karasubazar. Outre la langue locale, ils adoptèrent également le mode de vie, les coutumes vestimentaires et l'architecture rurale de leurs voisins tatars, dont ils ne se distinguaient d'ailleurs que par leurs peotims, mèches de cheveux laissées à la hauteur des tempes, conformément à la loi religieuse juive. Ils allaient même jusqu'à se teindre les ongles et la paume des mains à la façon des Tatars (Rosenthal non daté, pp. 574-575).

D'autre part, aux côtés des Krimchaks vivait également en Crimée une communauté karaïte, confession dissidente du Judaïsme qui refuse la tradition talmudique au profit d'une observance stricte de la Torah. Ces Karaïtes s'exprimaient eux aussi en tatar, même s'ils enrichirent leur parler de nombreux mots d'origine hébraïque, arabe et persane, et même de tournures syntaxiques hébraïques. Il existait également des communautés karaïtes en Turquie - où ils étaient hellénophones - en Lituanie et en Pologne (Trevisan-Semi 1992, pp. 64 et 71).

Les Karaïtes écrivaient eux aussi le tatar à l'aide des caractères hébreux, le plus ancien ouvrage connu étant un hymne religieux rédigé... à Venise en 1528 ou en 1529. A côté d'une abondante littérature religieuse, se développa dès le $17^{\text {ème }}$ siècle une littérature profane, dans des registres aussi divers que la poésie, la prose et la comédie.

Les premiers ouvrages imprimés - dont une édition de la Bible - apparaissent au début du $19^{\text {ème }}$ siècle en Crimée, mais aussi à Istanbul (Zajaczkowski 1964, pp. $793 \mathrm{sq})$.

Mais la communauté karaïte ne compte plus aujourd'hui que quelques milliers de membres, la plupart installés en Israël, et ceux d'entre eux qui sont restés karaïmophones écrivent leur langue à l'aide des caractères latins depuis le début de ce siècle (Trevisan-Semi 1992, pp. 70 sq).

\section{En marge de l'Empire ottoman}

Dans le Caucase, plus particulièrement en Géorgie - contrée disputée dès le $16^{\text {ème }}$ siècle par les Ottomans et les Perses Safavides - une minorité d'autochtones devenus turcophones ont laissé à la postérité quelques textes en turc transcrits en caractères géorgiens. Certains de ces textes, datés du $19^{\text {ème }}$ siècle, ont un contenu profane (Türkmen 1983, pp. $173 \mathrm{sq}$ ). A côté de ces textes en turco-géorgien, hélas encore très peu étudiés, il existe même quelques textes en azéri rédigé avec l'alphabet géorgien (Samoïlovitch 1934, p. 962b).

De l'autre côté de l'Empire Ottoman, en Syrie, le turc devint l'une des langues liturgiques des Chrétiens monophysites, appelés aussi Jacobites, aux côtés du syriaque et de l'arabe. C'est ainsi que l'on a conservé deux manuscrits - l'un remontant au $16^{\text {ème }}$ siècle, le second du début du $19^{\text {ème }}$ siècle - provenant des environs de Ma- 
latya, en Turquie actuelle, qui furent rédigés en turc ottoman au moyen de caractères syriaques (Clogg 1968, p. 71).

Les Balkans et les contrées slaves furent également le théâtre de divers métagrammatismes à l'époque ottomane. Ainsi, les communautés musulmanes locales utilisaient quelquefois l'arabe pour écrire leur propre langue - ce qui constitue le phénomène inverse de ce que nous avons étudié jusqu'ici. Il arrivait par exemple que des poètes bosniaques composent leurs vers en serbo-croate transcrit en lettres arabes, tout comme les musulmans de Croatie et de Hongrie le faisaient dès le $16^{\text {ème }}$ siècle dans leurs langues respectives. Au siècle suivant, quelques Tatars écrivirent également des textes en biélorusse ou en ukrainien avec le même procédé (Bombaci 1969, p. 319 ; Köprülüzade 1934, p. 1002a ; Dachkévytch 1982, p. 395).

En Albanie aussi, les ashiqeris - poètes musulmans dont le nom s'inspire des Aşıks d'Anatolie - rédigeaient régulièrement leurs œuvres dans leur langue natale écrite en caractères arabes, comme par exemple Nezim de Premit au $18^{\text {ème }}$ siècle. Ce n'est qu'en 1908 que l'alphabet latin devint la règle officielle dans le pays (Rossi 1946, p. 219).

Enfin, signalons qu'en 1834 un missionnaire anglais, de passage à Plovdiv, en Bulgarie, rapportait que les Chrétiens de cette cité notaient le turc, en usage dans la ville, à l'aide de l'alphabet cyrillique (Rossi 1946, p. 187).

En marge de ces divers exemples de métagrammatisme, il faut mentionner quelques cas isolés, qui furent plus le fait de personnalités que de communautés.

$\mathrm{Au} 15^{\mathrm{èm}}$ siècle, un militaire transylvannien fut fait prisonnier par les Turcs, auprès desquels il resta pendant vingt ans en captivité. Il rédigea par la suite un ouvrage dans lequel il décrivait les us et coutumes de ses " hôtes ». Dans son livre, on peut notamment lire des chants du célèbre Yunus Emre, poète mystique anatolien du $13^{\text {ème }}$ siècle, transcrits en caractères gothiques (Bombaci 1969, p. 285).

Dans le même esprit, Balassa, considéré comme l'initiateur de la poésie lyrique hongroise, composa au $16^{\text {ème }}$ siècle quelques poèmes en langue turque mais en caractères latins (Bombaci 1969, p. 319), anticipant ainsi de quelques trois siècles la réforme d'Atatürk.

En 1767, des missionnaires catholiques européens rédigèrent un ouvrage contenant quelques passages du Nouveau Testament en turc rédigé en caractères latins. Cet ouvrage est aujourd'hui conservé à la Bibliothèque de Manchester (Clogg 1968, p. 65).

\section{b. Le Monde arabe}

\section{Les langues romanes et l'arabe}

En Andalousie, a fleuri dès l'arrivée des Arabes un genre poétique particulier, la $m u$ washshaha, affectionné tant par les poètes arabes que juifs, qui le firent passé de la tradition orale au régistre écrit dès le $10^{\text {ème }}$ siècle. On distingue trois genres de $m u$ -

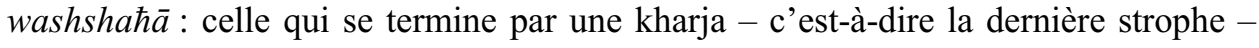


$m u ' r i b a$, « en arabe », celle qui se termine par une kharja 'āmma, « en arabe dialectal », et enfin celle dont la kharja est a'jamiyya, c'est-à-dire composée en langue romane vernaculaire transcrite en caractères arabes (Ihsān 'Abbās 1962, pp. 216 sq ; Deyermond 1987, p. 29). Ce dernier type de poèmes permet de se faire une idée de l'état des parlers romans parlés en Espagne à l'époque de l'occupation arabe.

Les Moriscos - les Musulmans qui restèrent dans la Péninsule ibérique après la Reconquista chrétienne, au $15^{\text {ème }}$ siècle - produisirent une riche littérature, tant religieuse que profane, appelée aljamiada (de l'arabe al-'ajamiyya, «qui n'est pas arabe »). Il s'agit, selon la région concernée, de textes rédigés en castillan, en aragonais, en galicien, en catalan voire même en portugais, transcrits en caractères arabes. Après avoir été expulsés d'Espagne en 1609 par le Roi Philippe III, ils perpétueront cette littérature au Maghreb (Lévi-Provençal 1978, p. 416a).

\section{Les Juifs dans le monde arabe : le cas du judéo-arabe}

Les Juifs, qui connurent si souvent le statut de minorité dans leur histoire, eurent très souvent recours à l'usage de leur propre alphabet pour noter la langue de la communauté dominante - ce qui renforce encore le concept général de clivage entre la langue dominante d'une part et l'alphabet de la culture de référence d'autre part.

Nous avons déjà abordé le cas des Krimchaks et des Karaïtes. On pourrait également ne fût-ce que citer le yiddish, le judéo-espagnol, le judéo-provençal, le judéo-italien, mais aussi le judéo-persan et même le judéo-tat (le tat étant une langue minoritaire se rattachant à la famille iranienne, parlée en Iran et dans le Caucase), toutes ces langues étant transcrites à l'aide des caractères hébreux (Lidzbarsky non daté, p. 446b).

Mais le cas le plus intéressant - notamment par la taille du corpus qui en subsiste - est sans doute celui du judéo-arabe, d'une importance fondamentale pour la culture juive, dont les témoins les plus anciens qui nous sont parvenus remontent au $9^{\text {ème }}$ siècle. Il s'agit d'arabe transcrit en caractères hébreux - quelquefois accompagnés de signes diacritiques - correspondant à un niveau de langue flottant entre la langue classique et l'arabe dialectal, que l'on appelle en fait le Moyen Arabe. Le judéo-arabe a connu un large succès, puisqu'il était utilisé tant pour la correspondance et les transactions entre Juifs arabophones que dans la littérature, sacrée et profane. De nombreux ouvrages de philosophie, de sciences, de médecine, de philologie, d'exégèse biblique, de théologie et dans une moindre mesure de poésie nous sont ainsi parvenus (Blau 1965 ; Blau - Vajda - Cohen 1960, pp. 312a).

$\mathrm{Au} 11^{\mathrm{ème}}$ siècle, des poètes juifs d'Andalousie comme Samuel Ha Nagid, Ibn Gabirol ou encore Juda Halevi se sont inspirés des muwashshaћās pour créer en hébreu le shir ezor. Il s'agit d'un poème rédigé en langue hébraïque, hormis la dernière strophe, rédigée en arabe ou en langue romane vernaculaire, voire dans les deux langues entremêlées (!), l'ensemble du poème étant transcrit en caractères hébreux (Itzhaki 1997, p. 67). Quant au célèbre philosophe juif du $13^{\text {ème }}$ siècle, Maïmonide - sur lequel nous aurons l'occasion de revenir - il a également rédigé la quasi totalité de son œuvre scientifique en judéo-arabe (Cohen 1978, p. 315a). 
Le judéo-arabe occupe toutefois une place particulière dans l'étude des métagrammatismes, en ce sens que la langue de la culture de référence - l'hébreu - présente un statut différent des autres langues de référence.

En effet, la «communauté de référence » des Karamanlıs et des Arméno-kıpçaks par exemple occupe un territoire historique - même s'il n'est pas politiquement indépendant - et est par ailleurs constituée de locuteurs d'une langue vivante: le grec, l'arménien. Par contre, les auteurs du judéo-arabes se réfèrent à une communauté religieuse qui n'a plus de territoire défini, et utilisent l'alphabet d'une langue « morte », certes encore largement utilisée à l'époque, mais dans le cadre restreint du culte et de la production écrite.

Un autre élément important, lié au précédent, est que si les Karamanlis et les Arméno-Kipçaks ignorent généralement le grec et l'arménien, de nombreux lettrés utilisateurs du judéo-arabe maîtrisent eux parfaitement l'hébreu. Ainsi, Maïmonide a-t-il rédigé sa Mishne Torah en hébreu, tandis que Juda Halévi a rédigé le fameux Kuzari - ouvrage religieux - en judéo-arabe mais aussi de nombreux piyyutim en langue hébraïque (Itzhaki 1997, p. 67).

Pourquoi dès lors rédigeaient-ils une partie de leurs écrits en judéo-arabe et non en hébreu ? Peut-être que le fait que l'arabe en permettait une plus large diffusion - tous les lecteurs potentiels ne maîtrisant pas l'hébreu. Mais alors pourquoi Maïmonide aurait-il nourri le projet de traduire son œuvre en hébreu, peu avant de mourir ? Et pourquoi ses œuvres furent-elles quand même traduites en hébreu après sa mort, notamment par Samuel Ibn Tibbon (Haddad 1998, p. 33) ?

Un autre élément de réponse est peut-être à rechercher dans le statut culturel de l'arabe à l'époque : pour reprendre l'exemple de Maïmonide, ne s'est-il pas forgé sa culture philosophique en arabe ? Outre les traités de philosophes arabes comme Al Farābī, Ibn Bāja et Ibn Sinnā, il aborde également la lecture des philosophes grecs - en particulier Aristote - dans leur version arabe (Haddad 1998, p. 71). La langue arabe présentait donc le double avantage pour les intellectuels juifs de l'époque d'une part de mettre à leur disposition un imposant corpus de textes, d'autre part d'avoir déjà créé tout le vocabulaire nécessaire pour aborder les divers domaines scientifiques. Certains auteurs judéo-arabes crurent d'ailleurs de leur devoir de se justifier sur ce point, soulignant le fait que le vocabulaire de l'hébreu ancien n'était plus suffisant pour s'exprimer de manière concise et qu'il était donc préférable de recourir à l'arabe (Blau - Vajda - Cohen 1960, p. 316a).

Notons que les ouvrages karamanlıs à caractère religieux reprennent eux aussi le vocabulaire théologique - musulman - existant en turc ottoman, comme bihimdillah pour signifier « avec la grâce de Dieu » ou dindar pour « pieux » (Luffin 1998, p. 26).

\section{Le copte}

Les Coptes, Chrétiens monophysites d'Egypte, utilisent comme langue liturgique le copte, dérivé de l'égyptien ancien mais déjà l'objet d'un premier métagrammatisme, puisqu'il est noté à l'aide de l'alphabet grec, additionné d'un certains nombres de caractères supplémentaires destinés à rendre des phonèmes inexistants en grec. Ici, ce 
premier métagrammatisme n'est pas lié à la culture de référence - les Coptes ne se considérant pas comme des Grecs.

On a par contre quelques textes arabes transcrits en caractères coptes. Le phénomène semble relativement ancien, le Musée Copte du Caire ayant conservé un manuscrit contenant des hymnes religieux rédigé au $13^{\text {ème }}$ siècle. $^{3}$

\section{Le karshūnī}

Les Jacobites de Syrie, qui suivent la doctrine chrétienne monophysite, ainsi que les Nestoriens et les Maronites, utilisent fréquemment depuis le $10^{\text {ème }}$ siècle l'alphabet syriaque afin de transcrire l'arabe, qui est peu à peu devenu leur langue vernaculaire, tandis que la langue syriaque était cantonnée au domaine cultuel (Troupeau 1978, p. 699a). Cette méthode de translittération est appelée karshūnī ou garshūn̄̄, terme à l'étymologie obscure. Elle est constituée des vingt-deux lettres de l'alphabet syriaque, dont six ont une valeur phonétique précisée par des points diacritiques particuliers, de manière à rendre la phonologie complète de la langue arabe (Costaz 1955, p. 2, note 1).

Certains chercheurs utilisent également le terme karshūnī pour désigner le $m a$ layam, langue dravidienne écrite en caractères syriaques par les Chrétiens de Malabar, en Inde (Troupeau 1978, p. 699a ; Jensen 1970).

\section{Autres cas similaires}

Il faut mentionner le cas du maltais, qui présente le phénomène inversé : bien que l'occupation de Malte par les Arabes cessa en 1090, et que les derniers Arabes musulmans séjournant sur l'île en furent chassés en 1249, la langue parlée actuellement à Malte constitue toujours un dialecte arabe proche du parler de Tunis, enrichie de nombreux termes d'origine italienne, sicilienne et anglaise. Depuis 1934, le maltais s'écrit officiellement en caractères latins. Mais dès le $18^{\text {ème }}$ siècle les lettrés de l'île avaient déjà expérimenté des modèles de transcription italiens et arabes. Le plus ancien texte en maltais transcrit en caractères latins qui nous soit parvenu est un cantilène remontant au $15^{\text {ème }}$ siècle (Rossi 1991, pp. 280 sq).

Nous avons aussi pu constater personnellement que les arabophones de la région d'Antakya, en Turquie, qui ignorent quelquefois le turc, correspondent entre eux en arabe. Toutefois, nombre d'entre eux ignorent l'alphabet arabe et transcrivent donc leur dialecte arabe en caractères latins, de manière approximative.

\footnotetext{
${ }^{3}$ Musée copte de Mār Girgīs, Le Caire, n d'inventaire 4091.
} 


\section{Motivations}

\section{a. Motivations religieuses}

Mais pourquoi toutes ces cultures ont-elles eu recours au métagrammatisme ?

Selon quelques-uns, les métagrammatismes sont nés des mesures coercitives opérées par la culture dominante sur le plan intellectuel. Les autorités ottomanes auraient ainsi refusé que les Chrétiens utilisent les mêmes lettres que celles du Saint Coran. Plus tard, en 1843, une lettre écrite par un missionnaire protestant américain aurait été saisie parce qu'elle était écrite en arabe (Anhegger 1979-1980, p. 162).

Cela semble toutefois douteux, la Bible ayant déjà fait l'objet de traduction en arabe bien avant, en fait dès le $8^{\text {ème }}$ siècle (de Vaux 1971, p. 1236a). Peut-être s'agitil ici d'un cas isolé, ressemblant plus à une «tracasserie » de la part d'un gouvernement ottoman agacé par le prosélytisme très actif des missionnaires protestants qu'à une interdiction systématique.

Dans le même ordre d'idée, une légende populaire circulait en Anatolie, selon laquelle les Turcs avaient interdit aux Grecs de parler leur langue sous peine de se voir couper la langue ou même d'être exécutés (Clogg 1968, p. 60). Si des cas isolés de tels comportements ont pu exister, dans le chef de gouverneurs locaux ou par la pression populaire dans certaines régions, la survivance du grec - parfois à côté du karamanl - en Anatolie ne permet pas de suivre un tel raisonnement.

Si on met de côté la recherche d'explications coercitives au métagrammatisme, on peut se demander toutefois si les Karamanlıs, les Krimchaks et les autres n'ont pas décidé d'utiliser l'alphabet de leur culture d'origine pour garder un ultime lien avec elle, en particulier sur le plan religieux.

Certains prétendent donc que les Karamanlıs ont délibérément changé d'alphabet pour ne pas souiller les livres saints (Clogg 1968, p. 72). En effet la littérature karamanlıe étant à l'origine exclusivement religieuse, il aurait peut-être semblé indécent voire blasphématoire de citer la Bible en utilisant les caractères arabes, employés par les Musulmans pour leurs propres ouvrages religieux.

Cette attitude est bien sûr grotesque, puisque nous avons déjà mentionné l'ancienneté des traductions arabes de la Bible. Il n'en est pas moins très plausible que ce soit cette attitude qui ait motivé en partie ces métagrammatismes.

Il suffit de se rappeler la violente polémique engendrée par l'édition de la première traduction persane de la Bible en 1657. Hyde, l'auteur de cette version destinée à faire partie de la Bible polyglotte, avait rédigé le texte en caractères arabes comme l'aurait fait un Persan, ce qui provoqua la colère du clergé.

Une traduction persane du Pentateuque avait bien déjà été publiée par Taussen un siècle auparavant, en 1546 - en même temps qu'une version arabe d'ailleurs mais ces deux textes furent publiés à Constantinople en caractères... hébreux (Deny 1955, p. 31)!

Le cas du philosophe juif Maïmonide est particulièrement intéressant pour comprendre les rapports d'un auteur avec la langue de sa culture de référence, celle de la culture dominante et leurs alphabets respectifs. Il faut tout d'abord insister sur 
le fait que Maïmonide a rédigé l'ensemble de son œuvre en judéo-arabe, sauf quelques rares écrits dont sa Michne Torah, qu'il a rédigée entièrement en hébreu (Haddad 1998, p. 33). Ici, le facteur religieux est évident : l'auteur rédige toute son œuvre en judéo-arabe, y compris ses traités religieux, mais la Michne Torah se situe à un autre degré de sacralité, il la rédige donc en hébreu.

D'autre part, il est intéressant de souligner que Maïmonide avait interdit de transcrire ses ouvrages en judéo-arabe en caractères arabes, interdit qui n'a d'ailleurs été transgressé qu'au siècle passé dans une édition turque du Guide des Egarés (Haddad 1998, p. 33). Ici encore, le caractère sacré de la lettre semble plus que clair : si Maïmonide rédige des traités religieux en langue arabe, il est toutefois impératif qu'ils n'existent qu'en caractères hébreux.

De manière générale, certains intellectuels juifs utilisaient l'arabe au détriment de l'hébreu avec une certaine mauvaise conscience, ce qui explique que de nombreux textes présentent deux rédactions, l'une en judéo-arabe et l'autre en hébreu (Blau Vajda - Cohen 1960, p. 316b).

Un autre élément à classer dans le domaine des motivations religieuses, quoique secondaire, est le désir de détourner le lectorat juif d'une certaine littérature populaire musulmane, en rédigeant des textes d'un genre similaire, avec une langue similaire, mais qui se réfère à la culture biblique (Blau - Vajda-Cohen 1960, p. $317 b)$.

D'ailleurs, dès le $16^{\text {ème }}$ siècle, les intellectuels juifs favorisent à nouveau l'hébreu pour leurs écrits religieux tandis que le judéo-arabe est désormais cantonné à une certaine littérature - poésie liturgique, instruction religieuse, culture profane destinée aux couches les moins instruites de la population juive (Blau - Vajda - Cohen 1960, p. 317b).

Mais l'alphabet revêt aussi pour ses utilisateurs un caractère magique. Ainsi, certaines lettres de l'alphabet grec étaient interprétées comme des symboles de concepts ou de personnages clés du christianisme (Fevrier 1984, p. 592). Dans ce domaine, le cas du judéo-arabe est toutefois le plus parlant en raison du développement de la notion de sacralité de la lettre dans la culture juive, et ce dès avant la naissance de ce métagrammatisme. Les caractères de l'alphabet hébraïque ont en effet un sens intrinsèquement sacré : selon la tradition mystique - qu'on se réfère ici au Sefer Yetsira, au Sefer ha Temūna ou au Sefer ha Zohar - Dieu a créé le Monde à l'aide des lettres de l'alphabet. La même tradition mystique donnera lieu à diverses disciplines ayant pour objectif l'interprétation des lettres de l'alphabet selon leur aspect formel ou leur valeur numérique : la gematria, le tserūf ou le notariqon (Cohen 1997, p. 236 ; Eco, 1994).

Un autre exemple allant dans ce sens est celui des Arméniens catholiques uniates, qui adoptèrent délibérément le turc comme langue vernaculaire, ne conservant l'arménien que comme langue liturgique, et ce de manière à se démarquer des Arméniens orthodoxes (Berberian 1963, p. 809). 


\section{b. Motivations culturelles}

Jusqu'au $19^{\text {ème }}$ siècle, où de plus en plus de communautés deviendront perméables aux idées nationalistes européennes, l'identification nationale se confond en effet à l'identité religieuse, la langue et les traditions jouant un rôle secondaire.

Ainsi, dans la zone culturelle qui nous intéresse, un Grec qui se convertissait à l'Islam devenait en même temps un Turc. Les textes parlent quelquefois à propos du millet orthodoxe grec de ghenos tôn orthodoxôn, ou encore de ghenos tôn pistôn, littéralement de la «race des orthodoxes» ou de la «race des croyants». De la même manière que le Patriarche de Constantinople est aussi l'ethnarque, le « chef de la nation » (Argyriou 1981, pp. 136 sq).

Pour donner un exemple extrême de ce phénomène, signalons qu'au $18^{\text {ème }}$ siècle les Arméniens du Khemshin, dans les montagnes du Lazistan, au Nord-Ouest de l'Anatolie, furent contraints de se convertir à l'Islam. Ils s'assimilèrent alors aux Turcs, se considérant comme tels tout en continuant à pratiquer leur langue. Si bien qu'au $20^{\text {ème }}$ siècle cette petite communauté avait oublié ses origines arméniennes et ignorait même que la langue qu'elle parlait était de l'arménien (Dumézil 1964, p. 6)!

Dans cette optique, si on considère par exemple que les Karamanlis sont effectivement d'origine grecque, l'alphabet grec était peut-être l'ultime trace de la continuité - réelle ou feinte, mais en tous les cas désirée - entre leur ancienne et leur nouvelle culture, restant ainsi conscients de leurs origines, et conservant l'écriture comme preuve de leur grécitude. Il en va de même pour l'arménité des Arméno-Kipçaks. De la même manière que pour un Juif, écrire la langue qu'il parle - celle de la culture dominante - dans son propre alphabet lui permet de lui donner symboliquement une nature proprement juive (Daniels - Bright 1996, p. 727).

\section{c. Le concept de langue secrète}

Un autre aspect possible, même s'il semble secondaire à long terme, est de recourir au métagrammatisme pour se protéger des interprétations de l'autre. En effet, les Karamanlis, les Krimchaks, les auteurs judéo-arabes ont d'abord développé une littérature religieuse, de facto opposée à la doctrine musulmane, la version du Livre Saint des Juifs et des Chrétiens étant jugée par celle-ci comme ayant été falsifiée. Conserver un alphabet qui permettait de cacher le texte aux représentants de la culture dominante permettait de ne pas engager de vaines polémiques.

La rédaction de textes critiques par rapport à l'Islam et aux musulmans - comme religion mais aussi comme autorité politique - dans leur propre langue mais dans un alphabet qui leur était inconnu, offrait assurément un moyen sûr de les faire circuler en limitant les risques pour leur auteur. Pour reprendre encore une fois l'exemple de Maïmonide, ses Epître sur la Consolation, Epître sur la Persécution et Epître aux Juifs du Yémen, dans lesquelles notamment il conseille ses coreligionnaires quant à l'attitude à adopter par rapport aux tentatives de conversion forcée de la part des musulmans, ont certainement pu circuler plus facilement parce qu'il les 
rédigea en judéo-arabe. Du reste, il utilisa le même procédé que pour le reste de son œuvre, polémique ou non...

Si cet élément a donc pu jouer un rôle dans le métagrammatisme, il ne fut que secondaire et il s'est par ailleurs certainement estompé avec le temps. En effet, des traductions de la Bible et de divers textes religieux en arabe et plus tard en turc ottoman existaient parallèlement à ces textes en «alphabet secret», et ce dès l'aube des contacts entre toutes ces cultures. Nous avons vu que la plus ancienne traduction des Evangiles en arabe remonte au $8^{\text {ème }}$ siècle. D'autre part, au lendemain de la chute de Constantinople, le Sultan ottoman Mehmet II lui-même demanda au Patriarche orthodoxe Ghennadios Scholarios qu'il rédigeât L'exposition de la Foi chrétienne afin qu'il comprenne les fondements de la religion de ses sujets chrétiens (Clot 1990, p. 146).

Par ailleurs, la plupart de ces cultures ont développé une littérature profane, qu'il n'était donc plus besoin de cacher des autres puisqu'elle n'était plus l'objet possible d'interprétations. Et ce d'autant plus que cette littérature profane se rapprochait plus de celle de la culture dominante que de celle de la culture de référence : les livres de divertissement karamanlıs sont résolument anatoliens - épopée de Köroğlu, récits d'Aşık Garip... -, de même que le shir ezor s'inspire ouvertement de la muwashshaћa.

Toutefois, le caractère secret du métagrammatisme dépassait le monde sacré et permettait par exemple aux commerçants d'une communauté particulière d'effectuer des transactions protégées du regard des concurrents des autres communautés. Les nombreux documents non-sacrés en judéo-arabe - contrats, actes, correspondance... retrouvés au siècle passé dans la Geniza de la «Synagogue des Palestiniens », à AlFustāt (Egypte), témoignent de l'utilisation de cet alphabet à des fins profanes (Goiten 1965, p. 316b). L'écrivain canadien Naïm Kattan, d'origine judéo-irakienne, décrit dans l'un de ses romans la vie de la communauté juive de Bagdad de l'entredeux-guerres. Son récit foisonne de renseignements intéressants sur les rapports qu'entretenaient les Juifs avec la langue arabe. Il explique notamment que les commerçants juifs de Bagdad écrivaient en $s \bar{u} q \bar{\imath}$ - appellation du judéo-arabe en Iraq pour se protéger de la lecture des marchands non-juifs, et que le «Bureau de censure » de l'état irakien avait à sa disposition des employés chargés de transcrire les documents judéo-arabes en caractères arabes afin de s'assurer du caractère non subversif desdits documents (Kattan 1975, p. 129). En outre, Goiten cite le cas d'une lettre en judéo-arabe retrouvée à la Geniza, adressée par un parent d'élève au professeur de ce dernier. Selon lui, le père a eu recours aux caractères hébreux parce que son fils ne les maîtrisait pas encore et était donc incapable de lire les échanges entre son père et son professeur (Goiten 1965, p. 316b).

Dans le même ordre d'idée, il existait dans le domaine de la langue parlée un argot arabe enrichi de termes araméens et hébreux, propre aux commerçants juifs de Libye (une pratique similaire semble également avoir eu cours dans les communautés juives de Tunis et d'Alger), qui leur permettait de communiquer sans être compris par les musulmans (Goldberg 1980, p. 80). 


\section{d. Motivations didactiques}

D'aucuns ont supposé que le métagrammatisme était un outil privilégié pour enseigner la langue dominante à l'intérieur de la communauté.

Dans le cas des Karamanlıs, l'alphabet grec aurait été préféré à l'alphabet arabe parce que ce dernier n'était pas du tout approprié à la langue turque et posait donc de nombreuses difficultés aux lecteurs (Salaville - Daleggio 1958, p. VIII).

Pourtant, le turc transcrit en caractères grecs sans points diacritiques - qui furent employés tardivement et de façon non-systématique - n'est certainement pas plus aisé à lire que le turc transcrit en alphabet arabe, d'autant plus que ce dernier avait été légèrement modifié pour s'adapter à la langue.

De plus l'utilisation des caractères arabes était généralisée depuis longtemps dans le monde turc, alors que les Karamanlıs de toute façon ignoraient - ou ne connaissaient plus - le grec.

D'aucuns pensent que la majorité de la population paysanne d'Anatolie étant analphabète, l'emploi des caractères grecs aurait facilité l'apprentissage de la lecture et de l'écriture grâce à l'activité des prêtres et des moines (Anhegger 1979-1980, p. 168).

Mais les prêtres et même le haut clergé karamanlı étant turcophones, l'emploi de l'un plutôt que l'autre alphabet n'aurait rien changé.

En ce qui concerne l'alphabet grec, il fut déjà adopté par les Coptes pour noter leur propre langue, mais étant donné les différences phonétiques entre les deux langues ils choisirent de l'enrichir de six lettres supplémentaires, plus ou moins inspirées de formes grecques, de manière à pallier la carence du premier alphabet (Lambdin 1983, p. 4).

De même, l'alphabet arabe utilisé pour écrire le turc ottoman possède cinq lettres supplémentaires dérivées des modèles existants, par le rajout de traits ou de points diacritiques (Mallouf 1863).

Contrairement à ces deux cas, les Karamanlıs se servaient à l'origine uniquement des 24 lettres de l'alphabet grec, sans y apporter aucune modification.

Cela pose bien sûr de nombreux problèmes de lecture, car certains phonèmes turcs ne peuvent être notés avec les caractères grecs. Il faut donc employer une lettre ayant déjà une autre valeur phonétique, ce qui ne permet pas de distinguer les phonèmes $<\mathrm{s}>$ et $<$ ş $>$ notés $\sigma$ par exemple, ou encore $<\mathrm{k}>$ et $<\mathrm{g}>$ transcrits par $\kappa$, ou $<\mathrm{u}>$ et $<\ddot{\mathrm{u}}>$ transcrits par ov.

Le contexte et une certaine habitude permettent évidemment de lire ces textes, mais le problème est accentué par le fait que la langue transcrite emploie régulièrement des tournures dialectales (Salaville - Dallegio, pp. 82-88), et que l'orthographe est très instable, ne suivant aucune règle précise mais plutôt l'intuition de l'auteur.

Dans d'autres cas, l'écrivain cultivé est influencé par l'orthographe du turc ottoman, ce qui explique des formes telles que olub à la pace de olup ou oldi à la place de oldu par exemple (Anhegger 1979-1980, p. 168). 
Néanmoins, la qualité de l'orthographe varie fort d'un livre à l'autre, et avec le temps et l'augmentation du nombre de publications certains auteurs tentent de pallier les inadéquations de l'alphabet grec.

Les Grecs de Mariupol, en Crimée, utilisaient également les caractères grecs pour transcrire le turc, comme nous le verrons plus loin. Et ils ajoutèrent une vingtcinquième lettre pour différencier le $<$ ş $>\mathrm{du}<\mathrm{s}>$ (Blau 1874, p. 589). Mais cette innovation resta limitée à Mariupol et ne fut jamais adoptée, voire jamais connue des Karamanlis.

Il faut attendre la fin du $18^{\text {ème }}$ siècle pour qu'apparaissent les premiers ouvrages imprimés avec des points diacritiques pour faciliter la lecture.

En 1784, un imprimeur grec, Dhimitrios, publie à Venise un ouvrage religieux destiné aux Orthodoxes d'Anatolie, où il expérimente quelques innovations : le $\mathrm{i}$ pour noter le $<\mathrm{i}>$ en début de mot, et le s surmonté d'un point (ś) pour noter le $<_{\text {Ş̧ }}>$ turc. Mais il n'applique pas encore systématiquement ces deux caractères dans son ouvrage (Salaville - Dalleggio 1958, pp. 82-88).

On ne retrouve pas l'emploi du $<$ s $>$ pointé avant 1799 , dans un ouvrage religieux publié par le Patriarcat du Fener à Istanbul, et encore une fois de manière sporadique (Salaville - Dalleggio 1958, p. 105).

En 1811, une édition karamanlıe des «Actes des Apôtres » publiée à Venise ajoute à côté $\mathrm{du}<\mathrm{s}>$ pointé le $<\mathrm{tz}>$ pointé pour transcrire le $<\mathrm{c}>$ turc et le $<$ oy $>$ pointé pour transcrire le $<\ddot{\mathrm{u}}>$, encore une fois, de façon non-systématique (Salaville Dalleggio 1958, pp. 148-151).

Mais hormis ces timides et incomplètes innovations, le système de transcription le plus adéquat ne viendra pas des Karamanlıs eux-mêmes mais de «l'English Bible Society », une mission prosélyte protestante très active, notamment en Anatolie. Ses disciples diffusaient de nombreux ouvrages religieux en karamanlı, en Anatolie et sur les côtes de la Mer Noire, ce qui leur valut d'ailleurs le courroux du clergé orthodoxe grec (Clogg 1968, p. 190 ; Anhegger 1979-1980, p. 174).

C'est ainsi qu'un certain Leeves, missionnaire anglais qui travaillait en collaboration avec l'imprimeur stambouliote De Castro, mit au point un alphabet grec avec points diacritiques pour pouvoir publier en 1826 une édition décente du Nouveau Testament en turc, encore améliorée au cours des éditions suivantes en 1836 et en 1838 (Anhegger 1979-1980, p. 172 ; Clogg 1968, p. 178).

L'emploi de ce nouveau mode de transcription, bien que très pratique puisqu'une fois mis au point il distinguait tous les sons de la langue turque, ne fut toutefois pas généralisé ultérieurement. Les éditions bon marché et la plupart des textes religieux, notamment ceux émanant du Patriarcat du Fener, continueront en effet d'employer l'ancien système.

Il faut très certainement imputer cette réticence à la réaction des autorités ecclésiastiques et des intellectuels karamanlıs contre les intrus protestants, pères de cette ingénieuse méthode de transcription.

Quelques auteurs et éditeurs karamanlıs proposeront encore de nouvelles transcriptions, comme P. A. Değirmenoğlu en 1886 ou N. E. Makris en 1891, mais 
ces initiatives isolées resteront sans échos, à cause de leur inadéquation ou de la complexité de leur emploi (Salaville - Dalleggio 1974, pp. 169 et 215).

Enfin, il est intéressant de noter la présence de points diacritiques sur une inscription lapidaire de la fin du siècle passé retrouvée à Niğde - en fait une stèle funéraire - alors qu'ils sont généralement délaissés par les tailleurs de pierre, sans doute par facilité ainsi que pour la raison citée plus haut (Eyice 1975, p. 42).

Dans le cas du judéo-arabe, certains auteurs ont également avancé qu'il fut élaboré car les Juifs des couches populaires parlaient certes l'arabe mais ne l'écrivaient pas. ${ }^{4}$ Mais encore une fois, l'argumentation semble assez faible car ces mêmes personnes ne connaissaient sans doute pas les caractères hébreux non plus, puisqu'il s'agissait alors d'une langue morte qu'ils étaient encore moins susceptible d'écrire que l'arabe...

Il ressort toutefois de ces diverses constatations que le métagrammatisme semble difficilement motivé par des raisons didactiques.

\section{Conclusion}

Une série de points communs entre la plupart des cas de métagrammatisme abordés ci-avant méritent d'être soulignés.

Tout d'abord, ils apparaissent au sein des cultures ayant une tradition historique et littéraire aussi large qu'ancienne. Dans le cas de l'Empire ottoman, cette ancienneté et cette importance sont d'ailleurs reconnues par leurs souverains ottomans, qui ont constitué chacune des cultures concernées en millet. Elles sont mises en minorité numériquement, mais surtout soumises politiquement à une culture ayant une autre langue et une autre religion, en l'occurrence la culture turque musulmane.

La différenciation confessionnelle, qu'elle soit voulue ou imposée de l'extérieur, est la référence systématique et constitue apparemment la raison principale du recours au métagrammatisme. On accepte d'écrire dans la langue de la communauté dominante - soit qu'on a oublié la langue de la communauté de référence, comme dans le cas du karamanl, soit que l'usage de la langue dominante permet une meilleure diffusion des écrits, comme dans le cas du judéo-arabe - par contre on ne transige pas sur la manière d'écrire cette langue : on a recours à l'alphabet de la culture de référence, même si l'usage d'un alphabet propre à la langue de la communauté dominante est parfaitement établi.

Le recours à l'alphabet de la culture de référence peut être quelquefois un simple moyen de conserver un lien symbolique avec ladite culture, d'autres fois il dépasse ce concept et est lié au caractère sacré - dans le sens premier, religieux - de la lettre.

Ensuite, la littérature issue de ces métagrammatismes naît exclusivement dans un contexte religieux - la rédaction de livres de prières, d'exégèses des Ecritures Saintes... - et évolue ensuite vers une production littéraire profane, quand le temps

\footnotetext{
${ }^{4}$ C'est l'idée qu'avance notamment Broydé (non daté, p. 51).
} 
lui en est laissé. Cela souligne encore une fois la volonté de se démarquer de la culture dominante sur le point religieux.

Par ailleurs, cette littérature profane est presque exclusivement inspirée de la culture dominante, créant par exemple dans l'Empire ottoman une dichotomie remarquable entre une littérature religieuse purement arménienne, grecque ou juive et une littérature populaire spécifiquement turque, à quelques tardives exceptions près.

Il faut toutefois préciser que certaines cultures ont développé une culture profane dans la langue de la culture dominante partiellement - ou largement - inspirée de la culture de référence, comme les Arméno-turcs et les Juifs dans le monde arabe.

Dans le même ordre d'idée, l'acculturation de ces communautés dépasse généralement le phénomène de métagrammatisme : la tradition orale, les habitudes vestimentaires, le comportement social se rapprochent fort des us de la communauté dominante : les Karamanlıs écoutent les aventures de Köroğlu, tandis que les Krimchaks se teintent les mains en rouge et que les poètes juifs d'Espagne s'inspirent de modèles arabes. Certaines de ces communautés se distinguent même assez de leurs coreligionnaires pour qu'un «ethnonyme» particulier - Karamanlis, Krimchaks, Urums - leur soit attribué.

D'autre part, sur le plan linguistique l'idiome utilisée est souvent plus proche du régistre populaire : le turc des textes karamanlıs est celui qui était parlé par la population, il est d'ailleurs tout à fait compréhensible pour le lecteur turc contemporain. Le fait est d'autant plus remarquable que le turc ottoman - qui était en usage pour la littérature à la même époque - est lui incompréhensible actuellement. De même, les textes rédigés en judéo-arabe par exemple sont beaucoup plus proche du moyen arabe que de l'arabe classique.

Les cultures ayant recours au métagrammatisme semblent donc se trouver dans un contexte politique et culturel assez similaire, et ont dès lors recours à un même réflexe culturel, même si chaque situation n'est pas identique. Certaines de ces langues sont déjà relativement bien étudiées. C'est le cas du judéo-arabe, incontournable pour lire des œuvres aussi fondamentales que celle de Maïmonide. D'autres comme le karamanlı ou l'arméno-turc ont déjà fait l'objet de quelques études, mais elles recèlent encore de très nombreux champs d'investigation qui n'attendent qu'à être défrichés : répertorier les nombreuses inscriptions disséminées en Anatolie, analyser les ouvrages religieux et les comparer aux textes grecs et arméniens, traduire la littérature populaire et la comparer à ses modèles turcs...

\section{Références}

Akbaș, P.(1992) : Librairie de Pera : Armenica. II. Istanbul.

Anhegger, R. F. M.(1979-1980) : Hurufumuz Yunanca. Anatolica Vol. 7, pp. 157-202.

Argyriou, A. (1980) : Nations et supra nations dans l'église orthodoxe à l'époque turque. In : Aspects de l'orthodoxie. Paris.

Balta, E. (1987) : Karamanlidika : $20^{\text {ème }}$ siècle. Bibliographie analytique. Athènes.

Berberian, H. (1963) : La littérature arméno-turque. In : Philologiae Turcicae Fundamenta. II, pp. $809-818$. 
Blau, J. (1965) : The Emergence and Linguistic Background of Judeo-Arabic. Oxford.

Blau, O. (1874) : Griechisch-türkische Sprachproben aus Mariupolen Handschriften. Zeitschrift des Deutsche Morgenlande Geselschaft Vol. 28, pp. 562-583.

Blau, J. - Vajda, G. - Cohen, D. (1978) : Judéo-arabe. In : Encyclopédie de l'Islam (2 ${ }^{\text {ème }}$ éd.), Vol. 4, Leiden-Paris, pp. 312b-321a.

Bombaci, A. (1969) : La letteratura turca. Milan.

Broydé, I. (non daté) : Arabic language. In : The Jewish Encyclopedia. Vol. 2, pp. 49-50.

Burguière, P. - Mantran, R. (1952) : Quelques vers grecs du $13^{\text {ème }}$ siècle en caractères arabes. Byzantion Vol. 22, pp. 63-80.

Clogg, R. (1968) : The Publication and Distribution of karamanlı. Texts by the British and Foreign Bible Society before 1850. Journal of Ecclesiastical Studies Vol. 19, 1, pp. 57-81 et 171-193.

Clot, A. (1990) : Mehmet II le conquérant de Byzance. Paris.

Cohen, J. (1997) : L'écriture hébraïque. Lyon.

Costaz, Y. (1955) : Grammaire syriaque. Beyrouth.

Courbage, Y. - Fargues, Ph. (1997) : Chrétiens et Juifs dans l'Islam arabe et turc. Paris.

Dachkévytch, Y. (1968) : L'établissement des Arméniens en Ukraine. Revue des Etudes Arméniennes Vol. 5, pp. 329-367.

Dachkévytch, Y. (1982) : Who are the Armeno-Kipchaks. Revue des Etudes Arméniennes Vol. 16, pp. $357-416$.

Daniels, P. T. - Bright, W. (1996) : The World's writing systems. New York-Oxford.

Deny, J. A. (1955) : A propos des traductions en turc osmanli des textes religieux chrétiens. Die Welt des Islams Vol. 4, pp. 30-39.

de Vaux, C. (1971) : Indjīl. In : Encyclopédie de l'Islam (2 ${ }^{\text {ème }}$ éd.), Vol. 3, Leiden-Paris, pp. $1235 \mathrm{a}-1238 \mathrm{~b}$

Deyermond, A. D. (1987) : Historia de la Litteratura española. Barcelona.

Dimitriev, N. K. (1934) : Azerbajdanische Lieder in armenischer Transkription. Wiener Zeitschrift Kunde des Morgenland Vol. 41, pp. 127-140.

Dumézil, G. (1938) : Les légendes du «fils d'aveugle». Revue de l'Histoire des Religions Vol. 142 , pp. 50-74.

Dumézil, G. (1964) : Notes sur le parler d'un Arménien musulman du Hemsin. Mémoire de la Classe des Lettres de l'Académie Royale de Belgique Vol. 57, No. 4.

Eckmann, J. (1991) : Karaman edebiyatı. In : Türk Dünyası Edebiyatı. Ankara, pp. 20-37.

Eco, U. (1994) : La recherche de la langue parfaite. Paris.

Eyice, S. (1975) : Anadolu'da karamanlica kitâbeler. Belleten Vol. 39, pp. 25-48.

Fevrier, J. G. (1984) : Histoire de l'écriture. Paris.

Geller, M. J. (1983) : More Graeco-Babyloniaca. Zeitschrift für Assyriologie Vol. 73, pp. 114-120.

Goiten, S. D. (1965) : Geniza. In : Encyclopédie de l'Islam (2 ${ }^{\text {ème }}$ éd.), Vol. 2, Leiden-Paris, pp. 1010-1012.

Goldberg, H. E. (1980) : The Book of Mordechai. A Study of the Jews of Libya. Londres.

Haddad (1998) : Maïmonide. Paris.

Hrbek, I. (1960) : Bulghār. In : Encyclopédie de l'Islam (2 ${ }^{\text {ème }}$ éd.), Vol. 1, Leiden-Paris, pp. $1344 \mathrm{~b}-1348 \mathrm{~b}$.

Ihsān 'Abbās (1962) : Ta'rīkh al-adab al-andalusī. Vol. 3, Beyrouth, Dār ath-thaqāfa.

Itzhaki, M. (1997) : Juda Halévi, D’Espagne à Jérusalem. Paris.

Jensen, H. (1970) : Sign, Symbol and Script. Londres.

Kähler, H. (1976) : Die Literatur der Kapmalaien. In : Handbuch der Orientalistik. Vol. 3, No. 1, Leiden-Cologne, pp. 316-321. 
Kattan, N. (1975) : Adieu, Babylone. Montréal.

Köprülüzade, F. (1934) : La littérature turque, 'othmanli, in Türks. In : Encyclopédie de l'Islam ( $2^{\text {ème }}$ éd.), Vol. 4, Leiden-Paris, pp. 988b-1010a.

Kramers, J. H. (1934) : Le turc 'othmanli. Langue et écriture, in Türks. In : Encyclopédie de l'Islam

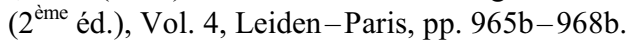

Lambdin, T. O. (1983) : Introduction to sahidic coptic. Macon.

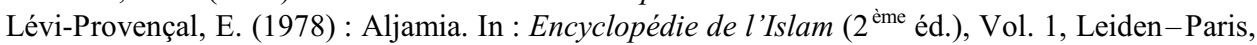
pp. $416 \mathrm{a}-417 \mathrm{a}$.

Lidzbarsky, M. (non daté) : The Hebrew Alphabet. In : The Jewish Encyclopedia. Vol. 1, New York, pp. $439-450$.

Luffin, X. (1998) : Une version karamanlı de l'épopée de Köroglu : mise en perspective culturelle. Archivum ottomanicum Vol. 16, pp. 5-99.

Luffin, X. (2000) : Baba Eftim et l'Eglise orthodoxe turque. Het Christelijk Oosten Vol. 52, pp. $73-95$.

Malherbe, M. (1995) : Les langages de l'humanité. Paris.

Mallouf, N. (1863) : Dictionnaire turc-français. Paris.

Maul, S. M. (1991) : Neues zu den 'Graeco-Babyloniaca'. Zeitschrift für Assyriologie Vol. 81, pp. 87-107.

Pamukciyan, K. (1991) : Ikinci Sultan Mahmud'a dair ermeni harflı türkçe dört maneum methiye. Belleten pp. 1053-1072.

Ricard, A. (1995) : Littératures d'Afrique noire. Paris.

Rosenthal, M. R. (non daté) : Krimchaks. In : The Jewish Encyclopedia Vol. 7, New York, pp. $574-575$.

Rossi, E. (1946) : Notizia su un manoscritto del canzionere di Nezim (secolo XVII-XVIII) in caratterie arabi ed in lingua albanese. Rivista degli Studi Orientali Vol. 21, pp. 219-246.

Rossi, E. et alii (1991) : Malta. Histoire, langue et littérature. In : Encyclopédie de l'Islam (2 ${ }^{\text {ème }}$ éd.), Vol. 6, Leiden-Paris, pp. 280a-288b.

Salaville, S. - Dalleggio, E. (1958) : Karamanlidika. I. Athènes.

Salaville, S. - Dalleggio, E. (1966) : Karamanlidika. II. Athènes.

Salaville, S. - Dalleggio, E. (1974) : Karamanlidika. III. Athènes.

Samoilovitch, A. (1934): Les langues turques. In : Encyclopédie de l'Islam (2 ${ }^{\text {ème }}$ éd.), Vol. 1, Leiden-Paris, pp. 956b-962a.

Spüler, B. (1986) : Kirim. In : Encyclopédie de l'Islam (2 ${ }^{\text {ème }}$ éd.), Vol. 5, Leiden-Paris, pp. $138 \mathrm{~b}-146 \mathrm{a}$.

Trevisan-Semi, E. (1992) : Les Caraïtes. Un autre Judaïsme. Paris.

Troupeau, J. (1978) : Karshūni. In : Encyclopédie de l'Islam (2 ${ }^{\text {ème }}$ éd.), Vol. 4, Leiden-Paris, p. $699 \mathrm{a}$.

Türkmen, F. (1977) : Ermeni harfleri ile basılmış bir meddah hikâyesi kapucubaşı. Türk Folkloru Araştırmaları Yıllığı, pp. 277-293.

Türkmen, F. (1983): Ermeni ve Gürcü yazılı kaynaklarında Köroğlu'na ait şiirler. Türk Edebiyati Araştirmalari Dergisi Vol. 2, pp. 173-182.

Ursinus, M. (1993) : Millet. In: Encyclopédie de l'Islam (2 ${ }^{\text {ème } e ́ d .), ~ V o l . ~ 7, ~ L e i d e n-N e w ~ Y o r k, ~}$ pp. $61 \mathrm{a}-64 \mathrm{~b}$.

Zajaczkowski, A. (1964) : Die Caramaische Literatur. Philologiae Turcicae Fundamenta. II. Wiesbaden, pp. 793-801. 